\title{
Influence of the surface layer characteristics on the regularities of the cutting process
}

\author{
Dmitriy V. Kraineve, ${ }^{1, *}$ Maria Yu. Polyanchikova ${ }^{1}$, and Alexander A. Bondarev ${ }^{1}$ \\ ${ }^{1}$ Volgograde State Technical University, Linine Ave. 28, Volgograde 400005, Russia
}

\begin{abstract}
The article considers the influence of the surface layer characteristics on the regularities of the cutting process and the formation of the quality of the surface machined. This effect has been confirmed by the study results of the combined cutting method with advanced plastic deformation (APD). The work estimates the impact of the change in the surface layer properties on the forces and temperature of cutting, stability of the chip formation and quality parameters of the surface machined.
\end{abstract}

The rise in the tech level specifies the challenges of increasing the effectiveness of the parts production and formation of the required performance characteristics of their surfaces. It is noteworthy that at present, inadequate attention is paid to all the parameters of the machine part surface both in construction, process design, and production. Machining considers for the most part the geometrical parameters and surface roughness. To improve the surface performance parameters such as the surface structure, hardness, wear resistance, etc., some special operations are assigned, including the strengthening treatment, honing finishing operations and heat treatment of various types. However, in certain cases, the desired surface parameters can be achieved by less number of operations and at less cost.

Besides, the concept of machining design, in our view, requires some updating and improvements. Despite the continuing technological advance and potential of certain branches of machine-building industry, which are the basis for any industrial production (first of all, machine tool building, metallurgy, cutting tool production, etc.), for upward movement, they cannot fully ensure the necessary stability of all technological system parameters in course of machining operations. So, this fact causes the parameter instability of the surface machined, and hence the performance instability of the manufactured parts, assemblies, mechanisms, and machines.

The machining procedure of a part can be considered as a sequence of operations on a workpiece. Each operation to some extent changes a set of the surface parameters of the workpiece machined, with the processing result to depend not only on the type and mode of exposure and the tool applied, but also on the previous state and the surface layer of the workpiece. The processing result depended not only on the type and modes of action and the tool applied, but also on the previous state of the workpiece and the surface layer. The effectiveness of the cutting process was considerably influenced by the properties of the material being processed, the workpiece and the cutting tool. The indicated properties given in the reference literature and certificates for tool and construction materials were averaged and allowed for a wide range of characteristics $[1,2]$. This significantly reduced the reliability and effectiveness of the technological preparation of production and also affected the stability of the processing results.

For a better understanding the essence of this issue, let's look at the physics of the cutting process. Cutting is a complex and specific form of plastic deformation and fracture, when high rates of deformation combine with extremely high pressures on the surface of the material processed, high temperatures and a gradient of stresses and deformations.

In edge cutting machining, at the shear moment, an elastic and then plastic deformation of the metal occurred at a certain point, while the tool undergoes elastic deformation. Hardening of the cutter-contacting layers of the material processed is accompanied by the release of heat, which is distributed into the workpiece itself, chips, cutting tools and the environment. The heat release intensity which depends on a set of parameters, including the characteristics of the material processed, tool, etc., and has a considerable effect on the nature of the cutting process. When the softening temperatures [3] are reached, the metal brakes down along the cutting line in the direction of the cutting wedge motion.

At the same time, due to the forward going deformation wave, the metal is reinforced again (the area of advanced hardening), and hardening of the metal under the surface machined also occurs due to the effect of the cutting edge on this area. So, there are permanent phenomena of hardening and softening of elementary metal layers.

Thus, the cutting process involves the interaction of two mutually opposite processes, i.e. the strain hardening and thermal softening.

\footnotetext{
* Corresponding author: krainevdv@mail.ru
} 
Since the strain hardening does not affect the entire volume of the workpiece, but primarily the surface layer, we can say that the maximum processing efficiency is impossible to achieve without taking into account the influence of the surface layer characteristics on the cutting process and the quality of the surface machined.

The significance of this effect has been confirmed by the results of studies of the combined cutting method with advanced plastic deformation (APD) $[4,5,6]$.

When using the APD, the metal, which had a lower plasticity than that in the case of traditional cutting, came into the area of the chip formation and hardening of the "chip-cutter" contact interaction zone. In addition, there was a weakening of the stress level in the primary deformation zone due to a decrease in the work to bring the volume of the treated body to fracture along the cutting line that helped to reduce the tangential component of the cutting force. The presented changes weakened the spread of the hardening zone of the height and length contact plastic deformations and also caused a decrease in the level of hardening of the secondary deformations zone and, consequently, resistance to the deformation. This was proved experimentally by the established fact of microhardness reduction on the chip roots (Fig. 1) in the APD turning.

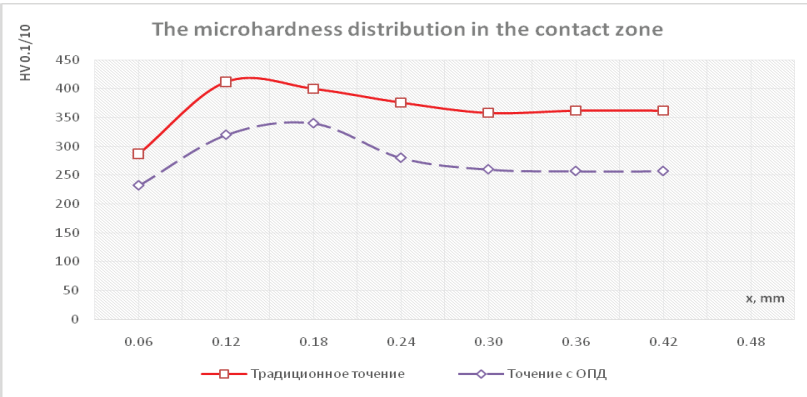

Fig. 1. The microhardness distribution in the contact zone on the front surface of the cutting edge at a distance of $10 \mu \mathrm{m}$ from the front surface in traditional turning and the APD turning (30XMA steel, hard alloy BK6; $\mathrm{t}=1 \mathrm{~mm} ; \mathrm{v}=90 \mathrm{~m} / \mathrm{min}$; so $=0.256 \mathrm{~mm} / \mathrm{rev}$. In the APD turning, the CAPD is 2).

To determine the mode of the APD application, the characteristic of the combined processing, i.e. "the ADP coefficient," was used $[4,5]$ :

$$
C_{A P D}=\frac{h_{h a r d}}{t},
$$

where $h_{\text {hard }}$ is the depth of the hardened layer resulted from the APD phase, $\mathrm{mm}$;

$t$ is the depth of cutting, mm.

The reduction of resistance to the plastic deformation when moving volumes of the material processed through the zones of the chip formation and contact interaction of chips with a cutting wedge determined the decrease in the heat release intensity.

The cutting temperature was measured by the artificial thermocouple method for the processing modes and conditions (Fig. 1). A reduction in the power of the heat source in the cutting zone was registered by $17 \%$ in the APD processing compared with the conventional turning. The reduction in the power of the heat source in the APD cutting was also established based on the measurements analysis of the natural thermocouple thermo-EMF (Fig. 2).

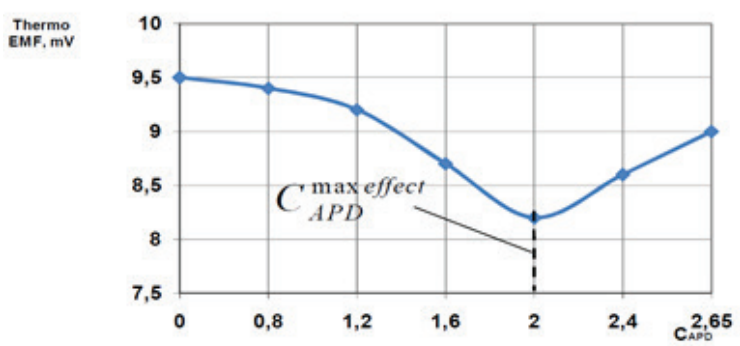

Fig. 2. The quantities of the thermoelectromotive force signal of the cutting process in traditional turning and the APD turning for different CAPD values (20X13 steel is T15K6 hard alloy, $\mathrm{t}=1 \mathrm{~mm}, \mathrm{v}=90 \mathrm{~m} / \mathrm{min}$, so $=0.256 \mathrm{~mm} / \mathrm{rev}$. CAPD $=0$ in traditional turning).

Analysis of the experimental data on the measurement of the thermo-EMF of the natural thermocouple confirmed the decrease in the cutting temperature in the APD turning (Table 1).

Table 1. The thermo-EMF signal values of the cutting process in traditional and APD turning, $\mathrm{mV}$

\begin{tabular}{|c|c|c|}
\hline $\begin{array}{c}\text { Processing modes and } \\
\text { conditions }\end{array}$ & $\begin{array}{c}\text { Traditional } \\
\text { turning E, } \\
\mathbf{~ m V}\end{array}$ & $\begin{array}{c}\text { ADP } \\
\text { turning E, } \\
\mathbf{~ m V}\end{array}$ \\
\hline $\begin{array}{c}\text { 20X13 steel is T15K6 hard } \\
\text { alloy; } \mathrm{t}=1 \mathrm{~mm} ; \mathrm{v}=90 \mathrm{~m} / \mathrm{min} ; \\
\mathrm{s}_{\mathrm{o}}=0.256 \mathrm{~mm} / \mathrm{rev} . \mathrm{In} \mathrm{APD} \\
\text { turning, the } C_{A P D}=2\end{array}$ & 9.5 & 8.2 \\
\hline $\begin{array}{c}14 \mathrm{X} 17 \mathrm{H} 2 \mathrm{steel} \text { is } \mathrm{BK} 6 \text { hard } \\
\text { alloy; } \mathrm{t}=0.5 \mathrm{~mm} ; \\
\mathrm{v}=135 \mathrm{~m} / \mathrm{min} ;\end{array}$ & & \\
$\begin{array}{c}\mathrm{s}_{\mathrm{o}}=0.166 \mathrm{~mm} / \mathrm{rev} \text {. In APD } \\
\text { turning, the } C_{A P D}=1.6\end{array}$ & 12.4 & 10.9 \\
\hline \multicolumn{2}{|c}{} & \\
\hline
\end{tabular}

The nature of the chip formation process was determined not only by the heat release intensity, but also by the laws of the heat distribution in the cutting zone. The intensity and direction of the heat fluxes in the cutting zone depended on the thermal conductivity $\lambda$ of the contacting materials. The application of the APD in this case had an effect on the thermal conductivity of the metal of the layer cut (Table 2).

Table 2. The values of the integral thermal conductivity of the initial and deformed material

\begin{tabular}{|c|c|c|c|}
\hline & Material & $\begin{array}{l}\text { Traditional } \\
\text { turning }\end{array}$ & $\begin{array}{c}\text { ADP } \\
\text { turning } \\
\left(\mathrm{C}_{\mathrm{ADP} \text { max. }}\right. \\
\text { efficiency. })\end{array}$ \\
\hline \multirow{2}{*}{$\begin{array}{c}\text { Heat- } \\
\text { conduction } \\
\lambda_{\text {total }} \\
\left(W /\left(m^{*} K\right)\right)\end{array}$} & $\begin{array}{c}20 X 13 \\
\text { steel }\end{array}$ & 21.7 & 11.17 \\
\hline & $\begin{array}{c}\text { 30XMA } \\
\text { steel }\end{array}$ & 35.08 & 31.07 \\
\hline
\end{tabular}


The decrease in the amount of the work, which was

integral sum of the stresses, acting in the zone of advanced hardening, contributed to a decrease in the value of the response applied to the front surface of the tool, i.e., the tangential component of the $P_{Z}$ cutting force when using the APD, on average by $15-20 \%$ (Fig. 3).

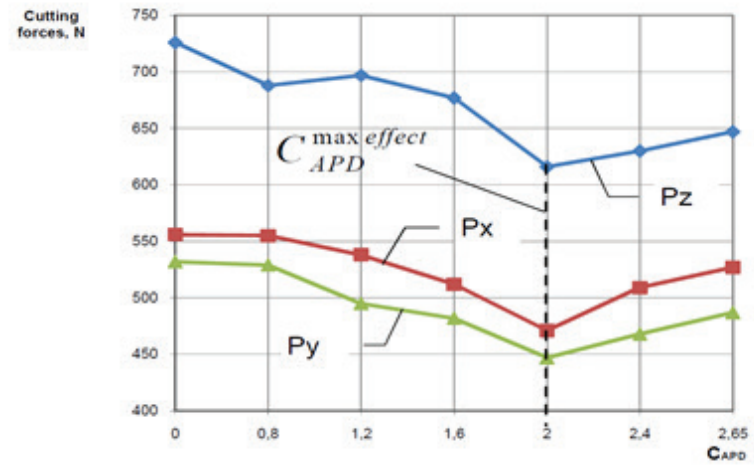

Fig. 3. The values of the tangential PZ, radial PY and axial PX components of the cutting force for traditional turning and APD turning for different values of the CAPD (20X13 steel is T15K6 hard alloy; $\mathrm{t}=1 \mathrm{~mm} ; \mathrm{v}=90 \mathrm{~m} / \mathrm{min}$; $\mathrm{so}=0.256$ $\mathrm{mm} / \mathrm{rev} . \mathrm{CAPD}=0$ in traditional turning.

The APD in turning ensures the reduction of the roughness parameters of the surface machined in comparison with the traditional turning (Fig. 4).

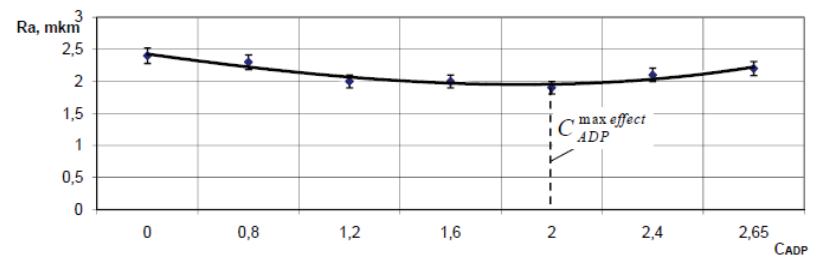

Fig. 4. Dependence of the mean arithmetic deviation of the $R a$ profile of the surface machined on the $C_{A P D}$ value (20X13 steel is T15K6 hard alloy; $v_{p}=90 \mathrm{~m} / \mathrm{min} ; s_{o}=0.256 \mathrm{~mm} / \mathrm{rev}$.; $t_{p}=$ $1 \mathrm{~mm}$; the $C_{A P D}=0$ in traditional turning).

In the APD turning, the size of the metal separation center along the cutting line decreased due to the stresses reduction in the cutting zone, and the destruction proceeded more stably, including due to the decrease in the plastic deformation instability under conditions of cyclic chip formation. In addition, the APD helped to reduce the values of the $R a, R \max , R z, S m$ parameters of the microrelief by reducing the wear of the blades.

Under the influence of the APD, the characteristics of the surface layer (the deformation degree and thermal conductivity) changed that affected the cutting process. required to remove the material layer and decrease in the

This action reduced the cutting forces and temperature, and the chip formation stability enhanced. This led to a change in the quality parameters of the surface machined, i.e., improvement of the surface micro-profile and, as a consequence, to an increase in the performance characteristics of the surface of the workpiece. Thus, it can be concluded that the characteristics of the surface layer have a significant effect on the regularities of the cutting process and the quality of the surface machined. However, up to the present time, theoretical relationships between the parameters of the surface layer, cutting process characteristics and performance properties of the parts have not been established. These dependences would allow solving the problem of technological support of the performance properties specified. The management of the technological processes to ensure the required state of the surface layer is based mainly on the accumulated production experience and results of the laboratory studies presented in the form of reference material and particular empirical formulas. This requires a theoretical generalization of the accumulated knowledge, establishment of theoretical and experimental dependencies of the characteristics of the surface layer, processing methods and regimes and the development of the control approach to the technological heredity in order to create optimal technological parts processing that provides the required quality of the surface machined, production level and minimum cost.

\section{References}

1. A.L. Plotnikov, Management of the cutting modes on lathes with CNC (RPK Politekhnik, Volgograd, 2003)

2. Ju.L. Tchigirinsky, Mathematical methods of the control of the machining processes (VSTU, Volgograd, 2010)

3. N.V. Talantov, Physics of the processes of cutting, wear and tear of tools (Mechanical Engineering, Moscow, 1992)

4. V.M. Yaroslavtsev, Bulletin of Bauman MSTU 1, 119 (2015)

5. D.V. Kraynev, Yu.N. Polyanchikov, A.A. Bondarev, Improving the turning efficiency of wrought steels and alloys with advanced plastic deformationm, (VSTU, Volgograd, 2015)

6. P.A. Norchenko, D.V. Kraynev, I.N. Kozachuhnenko, Procedia Engineering. 150, 821 (2016) 